\title{
Androgen receptor immunoreactivity in rat occipital cortex after callosotomy
}

\author{
G. Lepore, ${ }^{1}$ S. Gadau, ${ }^{1}$ A. Mura, ${ }^{1}$ B. Arru, ${ }^{1}$ G. Mulliri, ${ }^{2}$ M. Zedda, ${ }^{1}$ V. Farina ${ }^{1}$ \\ ${ }^{1}$ Department of Animal Biology, University of Sassari; ${ }^{2}$ Department of Biomedical Sciences, \\ Human Physiology Division, University of Sassari, Italy
}

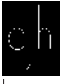

(C)2008 European Journal of Histochemistry

Gonadal steroidogenesis can be influenced by direct neural links between the central nervous system and the gonads. It is known that androgen receptor (AR) is expressed in many areas of the rat brain involved in neuroendocrine control of reproduction, such as the cerebral cortex. It has been recently shown that the occipital cortex exerts an inhibitory effect on testicular stereoidogenesis by a pituitary-independent neural mechanism. Moreover, the complete transection of the corpus callosum leads to an increase in testosterone $(T)$ secretion of hemigonadectomized rats. The present study was undertaken to analyze the possible corticocortical influences regulating male reproductive activities. Adult male Wistar rats were divided into 4 groups: 1 ) intact animals as control; 2) rats undergoing sham callosotomy; 3) posterior callosotomy; 4) gonadectomy and posterior callosotomy. Western blot analysis showed no remarkable variations in cortical AR expression in any of the groups except in group I where a significant decrease in AR levels was found. Similarly, both immunocytochemical study and cell count estimation showed a lower AR immunoreactivity in occipital cortex of callosotomized rats than in other groups. In addition, there was no difference in serum T and LH concentration between sham-callosotomized and callosotomized rats. In conclusion, our results show that posterior callosotomy led to a reduction in AR in the right occipital cortex suggesting a putative inhibiting effect of the contralateral cortical area.

Key words: androgen receptor, callosotomy, right occipital cortex, corticocortical connections, rat.

Correspondence: Gianluca Lepore,

Department of Animal Biology,

University of Sassari, Via Vienna, 2

07100 Sassari, Italy

Tel.: +39.079.229462.

Fax: +39.079.229432.

E-mail: lepore@uniss.it

Paper accepted on July 4, 2008

European Journal of Histochemistry

2008; vol. 52 issue 3 (July-September): 163-168
A ndrogen receptor $(A R)$ is a member of a superfamily of nuclear transcription factors mediating the action of steroid hormones (Prins, 2000). Traditionally, it is known to be expressed in many areas of the rat brain involved in neuroendocrine control of reproduction and growth, including the periventricular, paraventricular and arcuate nuclei, the ventral mamillary, dorsomedial nuclei and lateral hypothalamus (Simerly et al., 1990; Stumpf and Sar, 1978). Recent investigations demonstrated that AR can act as part of a neuroprotective and antioxidant system when activated by male steroid hormones (Ahlbom et al., 2001).

In addition to the classical intranuclear location, AR was also detected in axons and dendrites of rat forebrain suggesting a non-genomic mechanism of sex steroids that may not be attributed to transcriptional regulation (DonCarlos et al., 2003). There is considerable evidence to show that AR immunoreactivity is largely present in rat cerebral cortex where the majority of receptor-bearing cortical cells were found to be pyramidal neurons or, in a smaller amount, glial cells (DonCarlos et al., 2006). More precisely, that study highlighted the presence of ARpositive neurons in the occipital regions $\mathrm{Ocl}$ and Oc2 according to Paxinos and Watson (1997), as well as in other cortical areas such as sensory and motor regions (Kritzer, 2004).

There is growing evidence that brain areas, such as the caudal raphe nuclei, locus coeruleus, periaqueductal grey matter, are transneuronally connected with the gonads (Gerendai et al., 2000a; Gerendai et al., 2000b) and their involvement in a complementary control mechanism independent of the pituitary gland has been suggested. The role of this neural influence in the control of gonadal functions is consistently shown by studies based on transections or lesions in the peripheral or central nervous system (Gerendai et al., 1997; Banczerowski et al., 2001) and by recent observations showing an inhibitory effect of the right occipital cortex on tes- 
ticular steroidogenesis (Lepore et al., 2006).

Furthermore, it has been recently demonstrated that the complete transection of the corpus callosum leads to an increase in $T$ secretion of hemigonadectomized rats (Banczerowski et al., 2000), suggesting that the callosotomy-induced upregulation of testicular steroidogenesis is pituitary-independent. If so, it can be hypothesized that brain hemispheres, through callosal fibers, can reciprocally modulate the extrapituitary control of sex steroid production.

Therefore, the present work aimed to clarify how the right occipital brain cortex can be influenced by the contralateral cortical area. The hemisphere of the right side was chosen since most observations suggest that in both male and female rats there is a higher involvement of the right-sided brain structures in the control of gonadal functions (Gerendai et al., 1995).

\section{Materials and Methods}

All the experiments here described were performed according to the principles set out in the Declaration of Helsinki and approved by the Bioethics Committee of the University of Sassari, Italy. Adult male Wistar rats weighing $340 \pm 20 \mathrm{~g}$ were used. Animals were housed in a temperaturecontrolled room $\left(22 \pm 2^{\circ} \mathrm{C}\right)$ with a 12 -hr. light/dark cycle and fed on a standard diet and water. The animals were divided into 4 groups and underwent the following procedures: I) intact animals $(n=6)$, II) sham callosotomized rats $(n=6)$, III) posterior callosotomized rats $(n=6)$, IV) gonadectomized rats posterior callosotomized 14 days later $(n=6)$.

Rats from groups I, II and III were killed seven days post-surgery and those from groups IV seven days after the last intervention. For groups II and III, serum $T$ and LH levels were determined by radioimmunoassay (RIA) as previously described in detail (Lepore et al., 2006). To perform posterior callosotomy, rats were anesthetized with zolazepam and tiletamine (Zoletil, Virbac, $50 \mathrm{mg} / \mathrm{kg}$ ) and placed on a stereotaxic frame with the head in a $3.3 \mathrm{~mm}$ dorsoventral nose-down position relative to the interauricular line (Paxinos and Watson, 1997). The scalp was cut along the midline and a $4 \mathrm{~mm}$ hole was drilled $3 \mathrm{~mm}$ lateral to the midline and 3 $\mathrm{mm}$ posterior to the lambda. The corpus callosum was transected according to the method previously described in the mouse by Schalomon and Wahlstein (1995) and modified by Banczerowski et al. (2000) for the rat. Co-ordinates of posterior callosotomy were as follows: $6 \mathrm{~mm}$ posterior and $0.4 \mathrm{~mm}$ lateral to the bregma; angle $0^{\circ}$ from vertical; depth of the incision $2.9 \mathrm{~mm}$. The sham brain operation included anesthesia, immobilization of the head in the stereotaxic frame as well as opening of the skull and the dura mater. In order to check the location and extent of callosotomy, brains were fixed in $10 \%$ formaldehyde, dehydrated in alcohol and paraffin embedded. Serial sections, $5 \mu \mathrm{m}$ thick, were stained according to Nissl's method. Bilateral gonadectomy was performed according to the surgical procedures performed by Turvin et al. (2007).

Three animals from groups I, II and III were anesthetized according to the same protocol described above, then perfused via the left cardiac ventricle with $100 \mathrm{U} / 10 \mathrm{~mL}$ heparinated saline followed by $300 \mathrm{~mL}$ of $4 \%$ buffered paraformaldehyde. Brains were postfixed in the same fixative solution for $4 \mathrm{hrs}$., dehydrated in ethanol and paraffin embedded. Serial sections of the forebrain, 10 $\mu \mathrm{m}$ thick, were treated according to the immunoperoxidase method for AR detection. In detail, sections were blocked for 20 mins. with normal goat serum and incubated overnight at $4^{\circ} \mathrm{C}$ with a polyclonal anti-androgen receptor antibody (20 $\mu \mathrm{g} / \mathrm{mL}$, Sigma) diluted 1:50, then for one hour in a secondary antibody (biotinylated goat anti-rabbit, Vector) diluted 1:250. After several rinses in $\mathrm{PBS}$, sections were incubated with avidin-biotin complex system (ABC, Vector) for 30 mins. The slides were then incubated with diaminobenzidine (DAB) for 1-5 mins.w and finally dehydrated and coverslipped. Slides were concomitantly processed by omitting the primary antibody or incubating sections with non-immune rabbit serum (negative control sections). Afterwards, sections were observed by means of a Olympus microscope and captured in bitmap format with a F-View digital camera. The occipital cortical regions (0c1 e 0c2) were selected and their area estimated by means of the validated Scion Image computer software (Scion Corporation). Computer-assisted counts of the immunoreactive cells were determined and expressed as number of positive cells $/ \mathrm{mm}^{2}$.

Brain occipital cortical areas from all groups of animals were immediately removed and homogenized in lysis buffer with protease inhibitor Roche Complete Mini according to Tabori et al. (2005). In 
order to rule out any possible difference in protein estimation and loading, protein concentrations were determined by a colorimetric assay (DC Protein Assay, Bio-Rad) setting the spectrophotometer (LKB) to $750 \mathrm{~nm}$. Aliquots ( $80 \mu \mathrm{g}$ of protein) were prepared in sample buffer $(62.5 \mathrm{mM}$ Tris- $\mathrm{HCl} \mathrm{pH}$ $6.8,20 \%$ glycerol, 2\% SDS, 5\% $\beta$-mercaptoethanol, $0.5 \%$ bromophenol blue). Proteins were separated on SDS-PAGE in $10 \%$ gel at $60 \mathrm{~mA}$ for one hour and then transferred onto nitrocellulose membranes (Trans-Blot transfer medium, $0.45 \mu \mathrm{m}$, Bio-Rad) using a semi-dry transfer unit at a constant current of 20 volts for 20 mins. The nitrocellulose membranes were blocked for one hour in $5 \%$ skim milk PBS and incubated overnight with the same anti-androgen receptor antibody $(2 \mu \mathrm{g} / \mathrm{mL}$ ) used in the immunocytochemical study. The membranes were then incubated with a 1:15,000 IgG anti-rabbit alkaline phosphatase-conjugated antibody (Sigma) for one hour and the reaction developed using nitro blue tetrazolium chloride/5-bromo4-chloro-3-indolyl-phosphate, toluidine salt (NBT/BCIP, Roche) as chromogen. A molecular weight marker (Color Burst Electrophoresis Marker, Sigma) was used to ascertain the molecular weight of the band observed. It ran between 210 (violet) and 90kD (pink), consistent with the $110 \mathrm{kD}$ molecular weight of $A R$, as reported in the literature (Prins et al., 1991). Finally, densitometric values of protein bands were quantified using the Scion Imaging computer software. Results of both densitometric and cell count analyses were statistically processed by analysis of variance (ANOVA) followed by Student-Newman-Keuls multiple comparison method. $p<0.05$ were considered significant.

\section{Results}

$\mathrm{Niss}$ 's staining of the site of the surgical lesions (groups III and IV) showed that posterior transection of the corpus callosum was performed according to the scheduled protocol and involved the whole thickness of the corpus callosum. The lesions produced a limited extracallosal inflammation (Figure 1). There was no difference in serum $T$ and $\mathrm{LH}$ levels determined by radioimmunoassay between sham-callosotomized (group II) and callosotomized rats (group III), whereas serum $T$ levels were $4.5 \mathrm{nmol} / \mathrm{L}$ for group I and $4.2 \mathrm{nmol} / \mathrm{L}$ for group II, and LH concentrations were $1.5 \mathrm{nmol} / \mathrm{L}$ for both these two latter groups.

Western blot technique revealed one band at $110 \mathrm{kD}$ in each sample examined. The right cerebral cortex from intact (group I), sham-operated (group II) and gonadectomized callosotomized animals (group IV) displayed approximately equal amounts of AR. By contrast, rats who underwent callosotomy (group III) showed a noticeable decrease in AR expression of about $60 \%$ of the maximum value, i.e. that of intact animals (Figure 2).

Qualitative analyses showed a difference in immunoreactivity in occipital areas $0 \mathrm{cl}$ and $0 \mathrm{c} 2$. Indeed, intact rats (group I) showed a high number

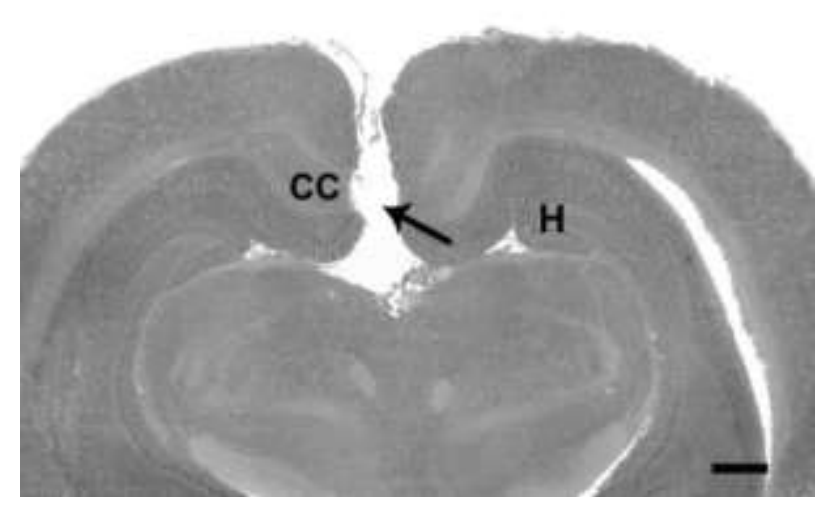

Figure 1. Rat brain coronal section showing the surgical lesion (arrow) strictly confined to the posterior part of the corpus callosum without involvement of other brain structures. Nissl's staining. $\mathbf{C C}=$ corpus callosum; $\mathrm{H}=$ hippocampus. $\mathrm{Bar}=1 \mathrm{~mm}$.

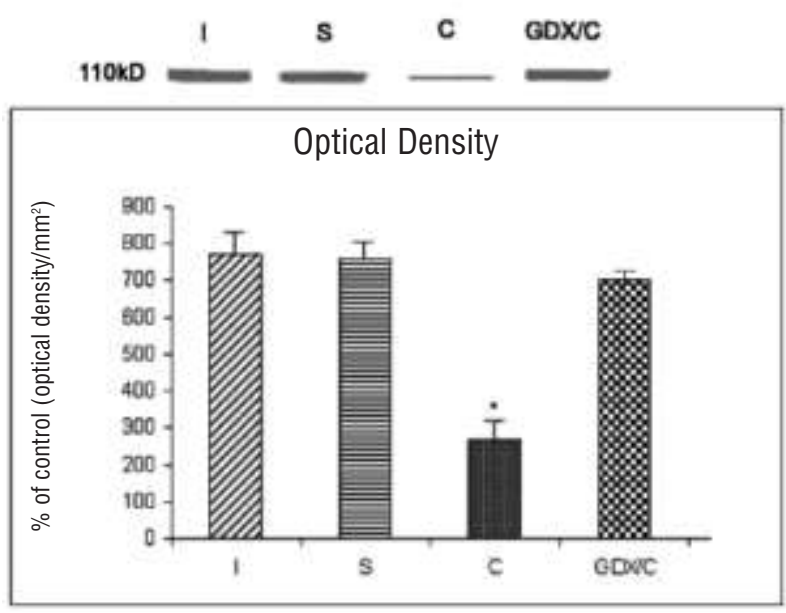

Figure 2. Western blot and densitometric analyses showing AR content in right occipital cortex of all experimental groups. Data are expressed as mean \pm SEM. Asterisk indicates significant difference $(p<0.05)$ from all other groups. I=intact animals; $S=$ sham callosotomized rats; $C=$ posterior callosotomized rats; GDX/C= gonadectomized rats posterior callosotomized 14 days later. 

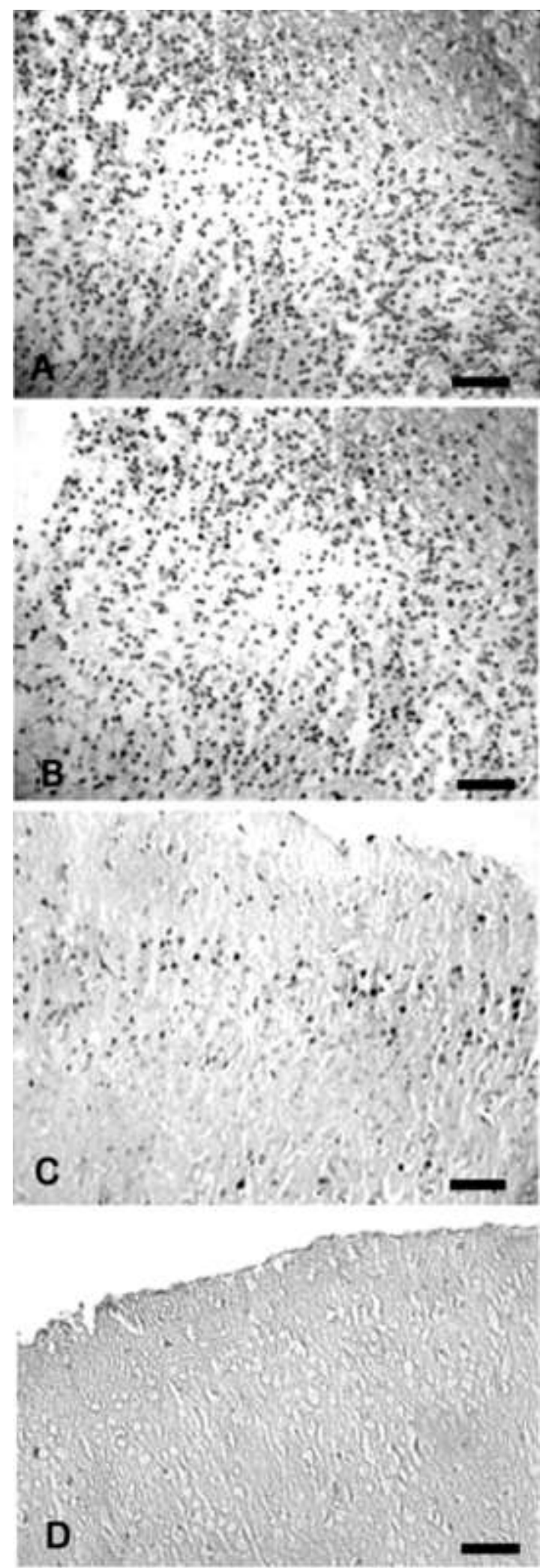

Figure 3. Qualitative analysis. AR immunoreactivity in sections from right occipital cortex of intact $(A)$, sham-callosotomized (B) callosotomized (C) rats and negative control sections (D). The lowest signal is detected in callosotomized rats, whereas intact and sham operated groups display the same AR immunoreactive pattern. Bar $=100 \mu \mathrm{m}$.

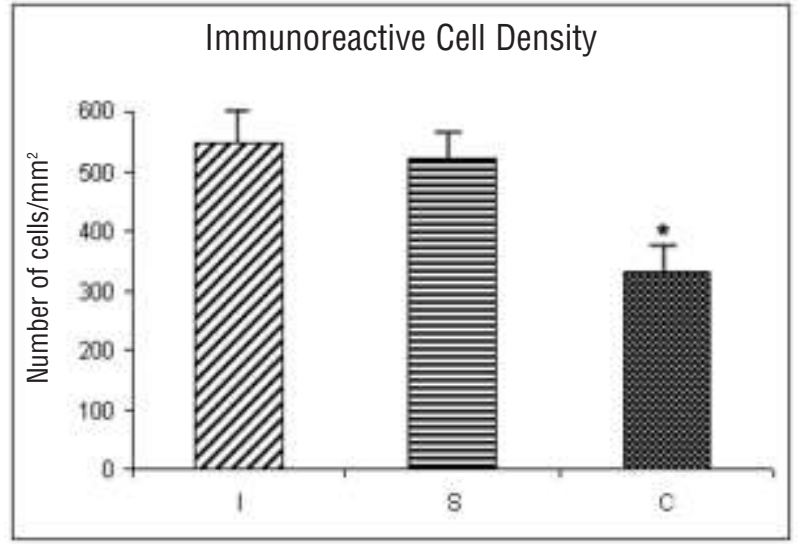

Figure 4. Quantitative analysis. The number of AR immunoreactive cells $/ \mathrm{mm}^{2}$ is significantly lower in callosotomized rats than intact and sham operated subjects. Asterisk indicates significant difference $(p<0.05)$. I=intact animals; S=sham-callosotomized rats; $\mathrm{C}=$ posterior callosotomized rats.

of nuclei with a marked immunoreactivity spreading all over the cortical layers. Such images (Figure 3a) mostly overlapped with those from sham operated animals (group II, Figure $3 b$ ). In contrast, the number of immunoreactive cells of callosotomized rats (group III) was significantly lower. Indeed, except for a few completely labeled neurons, immunostaining in those animals was confined to nuclei of cells mainly located in the II and III cortical layers (Figure 3c). Finally, no immunoreactivity was detected by omitting the primary antibody (Figure 3d).

Quantitative analysis carried out with the image software and expressed as immunoreactive-cell density $/ \mathrm{mm}^{2}$ confirmed the data obtained with Western blot and immunocytochemical methods. Indeed, in callosotomized rats the density of positive cells was reduced by approximately $40 \%$ in comparison with the values detected in intact and sham operated subjects respectively (Figure 4).

\section{Discussion}

The present work confirmed that AR immunoreactivity can be detected in the visual cortical areas $0 \mathrm{cl}$ and $0 \mathrm{c2}$ and, therefore, agrees with Kritzer (2004) who found AR expression in the pyramidal neurons of the visual areas of hormonally intact rats. Moreover, the results of our study show for the first time that posterior callosotomy leads to a decrease in the expression of $A R$ in right occipital cortex ( $0 \mathrm{cl}$ and $\mathrm{Oc} 2$ ), as shown by both immunocy- 
tochemical and Western blot analyses. The reduction in cortical AR immunoreactivity observed in callosotomized rats could be explained by the fact that the left hemisphere might exert a modulatory influence on $A R$ expression in the contralateral occipital areas. If so, it can be postulated that androgens produced by occipital neurons may paracrinally regulate cortical AR expression. Such androgen synthesis is in accordance with studies showing the presence of the complete machinery for androgen production in hippocampal neurons (Mukai et al., 2006). The right cortical disfacilitation determined by callosotomy may induce a significant increase in the locally produced androgens with a consequent downregulation of $A R$ expression. Indeed, it has been demonstrated that androgen receptor mRNA is inversely regulated by $T$ in adult mouse brain and an autologous downregulation of AR mRNA was found in several tissues such as prostate, epididymis, kidney and brain after androgen stimulation (Quarmby et al., 1990). In contrast, castration of adult male rats significantly increases AR mRNA in brain structures involved in reproductive activities such as the anterior pituitary gland and hypothalamic preoptic area (Kumar and Thakur, 2004). This is in accordance with our data showing that castration reduced the decrease in AR after callostomy (Figure 2).

In conclusion, our results suggest that in the right occipital cortical areas $0 \mathrm{cl}$ and $0 \mathrm{c} 2 \mathrm{AR}$ expression can be significantly influenced by the contralateral areas independently from the pituitary gland since LH serum levels did not change in either sham callosotomized or callosotomized rats. This is consistent with a previous study showing that right occipital decortication and posterior callosotomy resulted in changes in gonadal $T$ production in vitro without any significant variation on serum $\mathrm{T}$ and $\mathrm{LH}$ levels (Lepore et al., 2006). All these data are in accordance with other reports describing pure neural links between the nervous system and the gonads (Gerendai et al., 1986; Lee et al., 2002; Selvage et al., 2006). Thus, occipital cortex could be considered a part of the direct neural fine-tuning mechanism involved in the production of male testosterone. On the other hand, it has been shown that the occipital cortex is interconnected through temporolimbic structures with hypothalamic centers and brain stem nuclei (Banczerowski et al., 2003). Neural signals may then reach the testis via parasympathetic vagal fibers or via spinal cord and sympathetic nerves (Gerendai et al., 1997).

Further investigation is currently being carried out on the left hemisphere in order to verify whether cortical asymmetries occur between the occipital cortical areas of the two sides.

\section{Acknowledgments}

Work supported by the Fondazione Banco di Sardegna.

\section{References}

Ahlbom E, Prins GS, Ceccatelli S. Testosterone protects cerebellar granule cells from oxidative stress-induced cell death through a receptor mediated mechanism. Brain Res 2001;892:255-62.

Banczerowski P, Csaba Z, Csernus V, Gerendai I. The effect of callosotomy on testicular steroidogenesis in hemiorchidectomized rats: a pituitary-independent regulatory mechanism. Brain Res Bull 2000; 53:227-32.

Banczerowski P, Csaba Z, Csernus V, Gerendai I. Lesion of the insular cortex affects luteinizing hormone and testosterone secretion of rat. Lateralized effect. Brain Res 2001;906:25-30.

Banczerowski P, Csernus V, Gerendai I. Unilateral paramedian-sagittal brain cut extending from the level of the anterior commissure to the midlevel of the third ventricule above the amygdala affects gonadal function in male rat: a lateralized effect. Acta Biol Hung 2003; 54:79-87.

DonCarlos LL, Garcia-Ovejero D, Sarkey S, Garcia-Segura LM, Azcoitia I. Androgen receptor immunoreactivity in forebrain axons and dendrites in the rat. Endocrinology 2003;144:3632-38.

DonCarlos LL, Sarkey S, Lorenz B, Azcoitia I, Garcia-Ovejero D, Huppenbauer $\mathrm{C}$, et al. Novel cellular phenotypes and subcellular sites for androgen action in the forebrain. Neuroscience 2006; 138:801-7.

Gerendai I, Csaba Z, Csernus V. Lateralized effect of right- and leftsided vagotomy on testicular steroidogenesis and serum gonadotropin levels in hemicastrated peripubertal rats. Neuroendocrinol Lett 1995; 17:193-8.

Gerendai I, Halász B. Neuroendocrine asymmetry. Front Neuroendocrinol 1997;18:354-81.

Gerendai I, Nemeskéri A, Csernus V. The effect of neonatal vasectomy on testicular function. Andrologia 1986;18:353-9.

Gerendai I, Toth IE, Boldogkoi Z, Medveczky I, Halasz B. Central nervous system structures labelled from the testis using the transsynaptic viral tracing technique. J Neuroendocrinol 2000a;12:1087-95.

Gerendai I, Tóth IE, Boldogköi Z, Medveczky I, Halász B. CNS structures presumably involved in vagal control of ovarian function. J Autonom Nerv Syst 2000;80:40-5.

Kritzer M. The distribution of immunoreactivity for intracellular androgen receptors in the cerebral cortex of hormonally intact adult male and female rats: localization in pyramidal neurons making corticocortical connections. Cerebral cortex 2004;14:268-80.

Kumar RC, Thakur MK. Androgen receptor mRNA is inversely regulated by testosterone and estradiol in adult mouse brain. Neurobiol Aging 2004;25:925-33.

Lee $\mathrm{S}, \mathrm{Miselis}$ R, Rivier C. Anatomical and functional evidence for a neural hypothalamic-testicular pathway that is independent of the pituitary. Endocrinology 2002;143:4447-54.

Lepore G, Zedda M, Gerendai I, Csernus V, Gadau S, Manca P, et al. Right occipital cortex suppresses male rat testosterone secretion by a pituitary-independent mechanism. Neuro Endocrinol Lett 2006; 27:501-5.

Mukai H, Takata N, Ishii HT, Tanabe N, Hojo Y, Furukawa A, et al. Hippocampal synthesis of estrogens and androgens which are paracrine modulators of synaptic plasticity: synaptocrinology. 
Neuroscience 2006;138:757-64.

Paxinos $G$, Watson $C$. The rat brain in stereotaxic coordinates. San Diego/London: Academic Press, 1997.

Prins GS. Molecular biology of the androgen receptor. Mayo Clin Proc 2000;75:32-5.

Prins GS, Birch L, Green GL. Androgen receptor localization in different cell types of adult rat prostate. Endocrinology 1991;129:318799.

Quarmby VE, Yarbrough WG, Lubahn DB, French FS, Wilson EM. Autologous down-regulation of androgen receptor messenger ribonucleic acid. Mol Endocrinol 1990;4:22-8.

Schalomon PM, Wahlsten D. A precision surgical approach for complete or partial callosotomy in the mouse. Physiol Behav 1995; 57:1199-203.

Selvage DJ, Parsons L, Rivier C. Role played by brainstem neurons in regulating testosterone secretion via a direct neural pathway between the hypothalamus and the testes. Endocrinology 2006; 147:3070-75.

Simerly RB, Chang C, Muramatsu M, Swanson LW. Distribution of androgen and estrogen receptor $\mathrm{mRNA}$-containing cells in the rat brain: an in situ hybridization study. J Comp Neurol 1990;294:7695.

Stumpf WE, Sar M. Anatomical distribution of estrogen, androgen, progestin, corticosteroid and thyroid hormone target sites in the brain of mammals; phylogeny and onthogeny. Amer Zool 1978;18:435-45.

Tabori NE, Stewart LS, Znamensky V, Romeo RD, Alves SE, McEwen $\mathrm{BS}$, et al. Ultrastructural evidence that androgen receptors are located at extranuclear sites in the rat hippocampal formation. Neuroscience 2005;130:151-63.

Turvin JC, Messer WS Jr, Kritzer MF. On again, off again effects of gonadectomy on the acoustic startle reflex in adult male rats. Physiol Behav 2007;90:473-82. 